\title{
"Señor, por holgar con el cordón no querrás gozar de Melibea": la parodia del culto a las reliquias en la Celestina
}

\author{
ש \\ Santiago López-Ríos
}

Los santos vivían en el espíritu del pueblo justamente como dioses.

(Johan Huizinga 246)

Este artículo propone un nuevo análisis del simbolismo del cordón de Melibea en la Celestina y estudia cómo en el tratamiento de este motivo se desliza una durísima parodia del culto cristiano a las reliquias. Aparte de desentrañar las sutilezas con las que se construye la sátira, el objetivo también consiste en contextualizar esta postura intelectual demoledoramente escéptica ante tan arraigada manifestación de la religiosidad cristiana de la Edad Media. Este trabajo se suma, en fin, a los que reivindican el trasfondo del culto a los santos y de la hagiografía en la elaboración de la Tragicomedia (Dayle Seidenspinner-Núñez; Ángel Gómez Moreno; Ryan D. Giles 63-72).

El motivo del cordón aparece en la Celestina en una escena decisiva del acto IV. La alcahueta, atendiendo a los ruegos de Calisto de conseguirle a Melibea, ha llegado a casa de la joven con la excusa de vender un poco de hilado, untado con un aceite serpentino de presuntas propiedades mágicas. Tras intercambiar unas palabras con Alisa, la madre de Melibea, que se ausenta enseguida, Celestina y la doncella se enredan en una conversación fascinante, en la que importa, 
ante todo, el mensaje implícito. La hechicera se demora en desvelar la razón de su visita. Cuando menciona a Calisto, la hija de Pleberio y Alisa enfurece (por lo menos, en apariencia), pero se calma con una ingeniosísima excusa inventada por Celestina: Calisto padece dolor de muelas y podría sanar con una oración a Santa Apolonia conocida por Melibea y con el cordón de ésta (es decir, su ceñidor), de virtudes milagrosas por haber tocado cuanta reliquia hay en Roma y Jerusalén:

Melibea. ¿Poco calor? Poco lo puedes llamar, pues quedaste tú viva y yo quejosa sobre tan gran atrevimiento. ¿Qué palabra podías tú querer para ese tal hombre que a mí bien me estuviese? Responde, pues dices que no has concluido, y quizá pagarás lo pasado.

Celestina. Una oración, señora, que le dijeron que sabías de Santa Polonia para el dolor de muelas. Asimesmo tu cordón, que es fama que ha tocado todas las reliquias que hay en Roma y Jerusalem. Aquel caballero que dije, pena y muere dellas; ésta fue mi venida, pero pues en mi dicha estaba tu airada respuesta padézcase él su dolor en pago de buscar tan desdichada mensajera. ${ }^{1}$ (129)

Después de excusarse con Melibea por no haber sido más clara con su petición desde el primer momento, Celestina consigue salirse con la suya gracias a la complicidad de la joven, quien justifica su enfado por haberse puesto en peligro su honra. De las dos cosas solicitadas (el orden en la petición me parece relevante), la doncella entrega de forma inmediata ("luego") sólo la segunda (el cordón), mientras que ruega a la alcahueta que, si es necesario, regrese, de la forma más discreta posible, al día siguiente por la oración, pues su madre está a punto de volver:

MELIBEA. ¡Oh cuánto me pesa con la falta de mi paciencia! ¡Porque siendo él ignorante y tú inocente habés padecido las alteraciones de mi airada lengua. Pero la mucha razón me releva de culpa, la cual tu habla sospechosa causó. En pago de tu buen sufrimiento quiero cumplir tu demanda y darte luego mi cordón. Y porque para escribir la oración no habrá tiempo sin que venga mi madre, si esto no bastare, ven mañana por ella muy secretamente. (134)

La crítica celestinesca nunca ha dejado de comentar este pasaje. ${ }^{2}$ Resumiendo, podríamos decir que hay unanimidad en reconocer que el dolor de muelas de Calisto sirve como metáfora de su deseo sexual,

\footnotetext{
${ }^{1} \mathrm{~A}$ menos que se indique lo contrario, todas las citas de la Celestina siguen la edición de Francisco J. Lobera et al., (Fernando de Rojas [y "antiguo autor"]).

${ }^{2}$ Un estado de la cuestión puede verse en Fernando de Rojas (y "antiguo autor") (623).
} 
según Ángel Gómez Moreno y Teresa Jiménez Calvente demostraron con gran rigor, ampliando la lista de ejemplos aportados por otros estudiosos. ${ }^{3}$ La metáfora aún pertenece a la cultura popular de muchos países y, por supuesto, la captarían los primeros lectores de la obra. Para preservar la reputación de Melibea, Celestina requería un código lingüístico particular y lo encuentra en el lenguaje médico (George Shipley). También se ha analizado la dimensión erótica del cordón de Melibea, relacionándolo con su virginidad (Javier Herrero; Gómez Moreno y Jiménez Calvente 100-102; Marcelino V. Amasuno 162-63). Más debatida ha sido la propuesta de Alan Deyermond de que esta prenda se contagia funestamente de los poderes diabólicos del hilado. ${ }^{4}$

Interesa ahora subrayar que, como ocurre a menudo en la Tragicomedia, en este pasaje el erotismo envuelve el elemento religioso, representado por la referencia a la oración a santa Apolonia y a las reliquias. Con respecto a lo primero, Andrew Beresford ha llamado la atención sobre el hecho de que Apolonia es una santa problemática para la Iglesia porque su muerte fue en puridad un suicidio (42-45). En otro trabajo, fijándome en las claves cómicas, he concluido que Celestina espera de Melibea una plegaria del folklore médico-religioso. El humor permea la alusión a la oración a santa Apolonia de una forma sutil. Por un lado, sirve a las dos mujeres para comunicarse en clave. Melibea le da a entender a Celestina que no se le escapa la verdadera demanda: ¿una experimentada curandera como Celestina, orgullosa de su saber médico, carece de remedios caseros para un mal tan común como el dolor de muelas? Por otro lado, tratándose de oraciones que la Inquisición perseguía por sus elementos paganos, la religión se retrata como un rito que da cabida a las supersticiones más pintorescas. De esta manera, se enfatiza la burla que, sobra decirlo, supone que Melibea acceda a curar el dolor de muelas (entiéndase, el deseo sexual) de Calisto y que una plegaria a una santa sirva de metáfora de dicha aceptación (Santiago López-Ríos, "La oración a Santa Apolonia"). ${ }^{5}$

\footnotetext{
${ }^{3}$ Entre éstos, destaca el importante artículo de Javier Herrero. En fecha más reciente, Louise Vásvari ha regresado al asunto, añadiendo más ejemplos de diversas tradiciones literarias.

${ }^{4}$ En la misma línea de Deyermond se sitúa la reflexión de Javier Herrero: "I sustain that Melibea's girdle should be interpreted as an emblem of her acceptance to be so bound. Her offering it to Calisto, as well as her surrender to the needle, becomes an obvious submission to the Devil's bit, to lust. She will relieve Calisto of his toothache; she is willing to be enlazada, fastened to him by the girdle that so closely touches her “relics"' (145). Una sólida argumentación de cómo el cambio de Melibea puede explicarse sin basarse en la magia es la de Joseph T. Snow.

${ }^{5}$ Aquí conviene recordar la inteligente lectura de este fragmento propuesta por Jean Dangler, quien opina que "Rojas uses a number of strategies in La Celestina to subvert medieval textual models that supported women healers" (126).
} 
Como no les pasaba inadvertido a Gómez Moreno y Jiménez Calvente en su valioso artículo, la parodia se acentúa al atribuirse al cordón virtudes milagrosas por haber entrado en contacto con reliquias. ${ }^{6}$ En este aspecto, la clave está en cómo se filtran algunos detalles que distorsionan la representación realista de esta forma de espiritualidad cristiana.

Según han estudiado numerosos historiadores, la veneración de las reliquias y las rutas de peregrinación que en torno a ellas surgieron fueron básicos en el desarrollo del Cristianismo medieval, pero las implicaciones de todo esto transcienden lo meramente religioso, pues condicionaron la política, la economía y la sociedad. ${ }^{7}$ La obsesión por los vestigios sagrados, documentada por lo menos desde el siglo II, surgió tanto de la necesidad de un testimonio tangible de la fe y lo divino como del anhelo de poseer objetos protectores frente a las múltiples manifestaciones del mal y, muy en particular, por su presunta capacidad para sanar. La fiebre por coleccionar despojos de cuerpos de santos impulsó su compra-venta al mismo tiempo que robos sistemáticos (los llamados furta sacra). Una imparable demanda provocó que se venerasen objetos o piezas de ropa (conocidos como brandea) que los santos bien habían tocado o habían poseído, con lo que el culto y comercio de reliquias se multiplicó. Asimismo, se aceptaba que cualquier objeto que tocara una reliquia adquiría propiedades milagrosas (Jonathan Sumption 21-49; José Castillo Castillo). Eran lo que se ha llamado reliquias "representativas o de contacto" (Nicole Herrmann Mascard 45-49). En el siglo XV el dominico Félix Faber llevó a Tierra Santa una bolsa con joyas de amigos y puso estas alhajas en contacto con cuanta reliquia adoró en su viaje (Sumption 26). Fray Martín de Castañega, a principios del siglo XVI, tan preocupado por erradicar supersticiones, no condenaba usar el agua con que se lavaban las reliquias para beber o sanar ganados enfermos:

No es malo vsar del agua del lauatorio del cáliz donde algunas reliquias se han lauado, para beuer o derramar sobre algunos ganados enfermos, porque sin superstición alguna, por su deuoción, los hombres alguna vez

6"También habría mucho que decir sobre las virtudes del cordón de Melibea, que tantas reliquias ha tocado. En este plano, la burla no hubo de esperar a las corrientes erasmianas, como sabemos muy bien, sino que dejó testimonios desde el siglo XII" (Gómez Moreno y Jiménez Calvente 102, n45).

${ }^{7}$ Entre los abundantes estudios sobre las reliquias en la Edad Media, cabe destacar las monografías de Jonathan Sumption y Nicole Herrmann-Mascard. Panoramas muy claros aportan José Castillo Castillo y Francisco Márquez Villanueva (Santiago: Trayectoria 127-63), éste último con especial referencia al culto a Santiago en España. 
piden del azeyte de la lanpara que arde delante de la imagen del tal santo o del Sacratissimo Sacramento, y el lauatorio de las llagas de la ymagen de sant Francisco, no para vsar mal dello, saluo para recebirlo e vsar dello con mucha deuoción, desseando remediar sus passiones y enfermedades o de sus ganados. $(40)^{8}$

En su tratado sobre españoles en la Ciudad Santa (1504) Baltasar del Río da fe de la costumbre de tocar reliquias con rosarios en Roma, el lugar con más número de estos vestigios sagrados del Cristianismo (Castillo Castillo 33). El pasaje curiosamente documenta también la palabra Celestina:

Y es la uerdad: que no hallereys mas ordenes de estados en ellas: que de frayles en Roma ya delas honestas: entrando en las Romanas. Nunca hallareys moça sin uicia: y tal que mal año para Celestina y aun para Ampelisca que mas sepan: ya tiene $n$ ellas hechas otras estaciones extraordinarias: y delas ordinarias no perderían dia por la uida. pues si es iglesia titular y uan alla los Cardenales: antes se haria la fiesta sin el sancto que sin ellas. Andanse os la moça y la uieia con sus manoios de cuentas tocando reliquias. Pues si soys español y os ueen con buena capa: no dexara la uieia de demandaros: sabiendo lo meior que uos: que que reliquias son aquellas. . . (Carlos José Hernando Sánchez 232)

Los restos sagrados simbolizaban poder y estatus socio-económico para los que los atesoraban, ya fueran países, ciudades o personas particulares (Sumption 33-35; Castillo Castillo). Desde luego, la alcahueta sabe muy bien que detrás de la fiebre por las reliquias subyacen las pasiones humanas más materiales. Cuando Celestina pondera la fama del milagroso cordón de Melibea, lo hace de manera zalamera para elogiar, de paso, no sólo su condición de piadosa cristiana, sino también la alta situación de la doncella en la jerarquía de la ciudad y la gran fortuna de su familia, que puede permitirse semejante bien material y espiritual. Con sus calculadas palabras, Celestina recuerda a Melibea que a la joven se la conoce por todo ello, una forma de insinuarle que no obvia la importancia de salvaguardar su honra.

Igual de realista se antoja la mención de las virtudes curativas del cordón de Melibea, por lo visto, indiscutibles entre sus vecinos. Poner fin a enfermedades y padecimientos físicos era una de las razones primordiales para peregrinar, adorar reliquias y coleccionarlas. Enrique Fernández, recordando la advocación de origen medieval a la

\footnotetext{
${ }^{8}$ Sobre esta misma costumbre en la Edad Media escribe Sumption: "The dipping of relics in water or wine remained the commonest method of healing practised in the pilgrimage churches of the eleventh and twelfth centuries. It was a convenient way of parceling out the miraculous power of the relics among large numbers of people" (112).
} 
Virgen de la Cinta y a varias santas (santa Verónica, santa Ana) para aliviar dolencias ginecológicas, ha precisado que el cordón protegería a Melibea "de los desarreglos menstruales a los que su condición de doncella la expone especialmente" (163).

Sin embargo, detrás de los detalles realistas se intuye una ácida sátira de la veneración de las reliquias y de la creencia en sus virtudes sanadoras. Salta a la vista que la hipérbole (el cordón "ha tocado todas las reliquias de Roma y Jerusalem” [mi énfasis]) sustenta la parodia. La exageración, habitual en el lenguaje empleado por Celestina a lo largo de la obra, esconde aquí un escepticismo irónico respecto a la veneración de estos objetos sagrados y a la peregrinación a los lugares santos. Una observación filológica y de crítica textual apunta a que la sarcástica hipérbole pudo incomodar durante el proceso de transmisión de la Celestina. La tradición de la Comedia en este pasaje lee "todas las reliquias," mientras que la Tragicomedia lee "las reliquias," a secas, sin "todas" (Rojas, Celestina. Tragicomedia de Calisto y Melibea II: 89; Rojas [y "antiguo autor"] 422; Comedia de Calisto y Melibea 235). Aunque se podría explicar sin más como un simple error por omisión en el proceso de copia, quizás obedezca a un intento de rebajar la exageración y, en consecuencia, suavizar la sátira. ${ }^{9}$ Detalles eruditos aparte, estas variantes, que tanto matizan el significado, son ejemplo de lo que Ottavio Di Camillo llama "the evolutionary nature of the text" (106).

Al margen de la hipérbole, por supuesto, el núcleo de esta burla a la veneración de las reliquias radica en conceder una dimensión erótica a un objeto religioso. El humor, por encima de todo, deriva de que la joven sabe que su cordón no va a curar un dolor de muelas en el sentido literal y que lo que importa es el mensaje oculto. De esta manera, como siempre ha aceptado la crítica, con mucha ironía, se anuncia la entrega de la virginidad de Melibea, que se consumará más adelante. El simbolismo se ramificaría aún más si nos fijamos en algunos detalles. La comicidad se dispara, según Enrique Fernández, al asociarse cordón y dolor de muelas (entiéndase, mal de amores).

${ }^{9}$ La traducción italiana de 1506 traduce fielmente ("tutte le reliquie de Roma e Hierusalem" [An Edition of the First Italian Translation 103]), lo mismo que la latina de Barth de 1624 ("Pariter cingulum tuum quod fama est tetigisse omnes reliquias quae Romae et Hierosolymis sunt" [Pornoboscodidascalus latinus 136]). El Interludio de Calisto y Melibea traduce "And the gyrdle there thou weyrst about the/ So many holy relykys is hath towchyd/ That thys knygtht thynkyth his bote thou maist be." Antonio López Santos y Rubén Tostado González opinan que aquí el autor inglés "cuestiona la eficacia tradicionalmente atribuida a las santas reliquias" (Interludio de Calisto y Melibea 32, 102). 
Este último "queda así burlescamente equiparado a un desarreglo menstrual” (Fernández 163).

Las connotaciones eróticas del cordón de Melibea alcanzan su máxima complejidad en el acto VI, donde la parodia del culto a las reliquias se torna aún más incisiva. En casa de Calisto, la alcahueta le relata al joven su entrevista con Melibea. Lo hace poco a poco, dilatando el resultado final, para excitarlo sexualmente. Al mencionarle al enamorado el cordón por primera vez, aunque se ahorra la hipérbole que usó con Melibea, lo sigue definiendo como un objeto de propiedades milagrosas. La orgullosa Celestina disfruta jactándose de la inteligente argucia que le ha facilitado salir tan airosa en el acto IV: "Un cordón que ella trae contino ceñido, diciendo que era provechoso para tu mal porque había tocado muchas reliquias" (153). El acto de entrega del ceñidero a Calisto simboliza que la vieja está a punto de poner en sus manos el cuerpo de la muchacha: "toma este cordón, que, si yo no me muero, yo te daré a su ama” (155). Calisto empieza entonces a adorar la prenda como si de un objeto sagrado se tratase. El cordón se ha convertido ahora en una reliquia en sí mismo; no por haber estado en contacto con cuerpos de santos (lo que se ha olvidado de forma súbita), sino por haber tocado el cuerpo de Melibea, es decir, por su intrínseco valor erótico. El cordón-reliquia deviene en el acto VI una formulación más de la dicotomía eros/thanatos que estructura toda la obra:

Calisto. ¡Oh nuevo huésped! ¡Oh bienaventurado cordón, que tanto poder y merecimiento toviste de ceñir aquel cuerpo que yo no soy digno de servir! ¡Oh nudos de mi pasión, vosotros enlazasteis mis deseos! Decidme si os hallastes presentes en la desconsolada respuesta de aquella a quien vosotros servís y yo adoro, y por más que trabajo noches y días, no me vale ni me aprovecha. (155)

La alusión a los nudos del cordón de Melibea encubre otra broma subida de tono a propósito de lo sagrado. Se acostumbraba a hacer estos nudos en los ceñidores para conmemorar la Pasión de Cristo, lo cual dio pie a hipérboles sagradas en la poesía cancioneril del siglo XV. El tópico lo cultiva, por ejemplo, Juan Álvarez Gato, en una composición en el que el poeta compara su arrebatado sentimiento amoroso con la Pasión de Cristo:

Porque el Viernes Santo vido a su amiga hazer los nudos de la Passión en un cordón de seda 
Hoy mirándoos a porfía, tal pasión passé por vos, que no escuché la de Dios con la rabia de la mía.

Los nudos quen el cordón distes vos alegre y leda, como nudos de pasión, vos los distes en la seda, yo los di en el corazón.

Álvarez Gato también transita el motivo del enamorado que enloquece imaginando tocar una prenda de la dama en un poema que recurre a la hipérbole sagrada para ensalzar las virtudes curativas del manto de la mujer amada:

Yo me tengo asý creýdo, que sy a ty toca su manto avnque agora vas tollido, tornarás sano y guarido bien como si vuieses yelo acullá al Sepulcro Santo.

Sin embargo, de las llamativas diferencias entre los versos de Álvarez Gato y la Celestina destaca una: el poeta nunca roza la prenda de la dama, mientras Calisto transforma el ceñidor de Melibea en una reliquia que manosea en una lasciva adoración, como describe Celestina:

CAlisto. Cuanto dijeres, señora, te quiero creer, pues tal joya como ésta me trujiste. ¡Oh mi gloria y ceñidero de aquélla cintura, yo te veo y no lo creo! ¡Oh cordón, cordón! ¿Fuísteme tú enemigo? Di lo cierto; si lo fuiste, yo te perdono, que de los buenos es propio las culpas perdonar. No lo creo, que si fueras contrario, no vinieras tan presto a mi poder, salvo si vienes a desculparte. Conjúrote me respondas por la virtud del gran poder que aquella señora sobre mí tiene.

Celestina. Cesa ya, señor, ese devanear, que me tienes cansada de esc charte y al cordón roto de tratarlo. (156)

La imagen de Calisto, dominado por el deseo sexual, desgarrando el ceñidor de Melibea, funciona como premonición de su brutal comportamiento con ella durante los encuentros físicos de los amantes. "[N]o me destroces ni maltrates como sueles" (321), se quejará la protagonista en el acto XIX. En esta línea, Roberto González Echevarría, fijándose en que "[e]l cinturón ata, corta el cuerpo, separa sus miembros" y en que "[e]l cuerpo de Melibea nunca es visto en 
su totalidad por Calisto, sino desmembrado por el cordón," concluye que el ceñidor se vuelve metáfora del "consumo violento de su cuerpo [de Melibea] mediante el desmembramiento y descuartizamiento" (33-34). Pero hay más significados que se superponen a éste. Calisto confiesa sonar con ser él mismo el cordón, de tal forma que pudiera estar en contacto íntimo con el cuerpo de su amada:

Calisto. ¡Oh mezquino de mí, que asaz bien me fuera del cielo otorgado que de mis brazos fueras hecho y tejido, y no de seda como eres, porque ellos gozaran cada día de rodear y ceñir con debida reverencia aquellos miembros que tú, sin sentir ni gozar de la gloria, siempre tienes abrazados! ¡Oh qué secretos habrás visto de aquella tu excelente imagen! (156)

El erotismo ahora se ha desplazado al primer plano. El joven se excita palpando el cordón e imaginando el cuerpo desnudo de Melibea y, más en especial, sus "secretos." Advirtamos que Calisto emplea los términos "gozar" y "gloria," asociados en la obra desde la primera escena al placer sexual (López-Ríos, "Ver la 'grandeza de Dios' en la Celestina"). La obscenidad, de nuevo, penetra en la imagen religiosa: una prenda de ropa venerable porque ha tocado cientos de reliquias se convierte en una reliquia en sí misma digna de adoración, por haber rodeado la cintura de la doncella y porque ha visto sus "secretos." A mi juicio esto constituye un ejemplo de la "vuelta del revés del modelo hagiográfico" que de forma tan brillante ha estudiado Gómez Moreno en la Celestina ("Lecciones de hagiografía" 175). El cordón se carga de un fetichismo erótico que se añade al "fetichismo . . . más espontáneo y más vulgar" que conducía a tratar "los objetos más santos como si sólo fuesen objetos domésticos" (Huizinga 263).$^{10} \mathrm{El}$ juego burlesco desborda los límites: el cordón-reliquia se transforma inmediatamente en un juguete sexual con el que se entretiene Calisto en esta escena. Amasuno habla sin rodeos de "onanismo" (165-166). Sempronio lo dice a las claras: "Señor, por holgar con el cordón no querrás gozar de Melibea" (157). Sobra comentar el significado sexual de "holgar," pero nótese cómo Sempronio vuelve a emplear "gozar" en el sentido de placer carnal. ${ }^{11}$

${ }^{10}$ E. Michael Gerli había notado ya el fetichismo del cordón: "Según sus propias palabras, el deseo de Calisto tiene sus raíces en la vista y el placer producido por el acto de mirar, y se plasma a través de la obra en hechos claramente fetichistas y voyerísticos ... . El imperativo de ver y mirar llega a tal punto que se desplaza el deseo hacia los objetos asociados con lo deseado. Cuando los ojos de Calisto se fijan en el cordón, el ceñidor de Melibea se encierra en el círculo del deseo proyectado y logra momentáneamente sustituir la presencia de lo deseado" (196).

${ }^{11}$ Manuel da Costa Fontes interpreta que la reacción de Calisto se explica también por los poderes diabólicos que ha adquirido el cordón: "Love was believed to induce 
Si quién sabe qué había tocado el cordón de Melibea en sus viajes a Roma y a Jerusalén y por qué manos ha pasado, ahora continúa circulando entre las de un joven de apetito sexual desenfrenado y las de una vieja prostituta, con todas las connotaciones que esto suma, tratándose del símbolo de la virginidad de Melibea. Más todavía: no descartemos que en todas estas vueltas del cordón-reliquia de Melibea quizás se oculte una burlesca alusión a los frecuentes traslados de los despojos santos. El viaje de las reliquias ha sido siempre consubstancial en la historia de estos objetos (Gómez Moreno, Claves hagiográficas 116).

Celestina saldrá de casa de Calisto con el cordón y se lo guarda ("déjame llevar el cordón, porque, como sabes, tengo dél necesidad" [161]). Al final del acto IX, Lucrecia llega a su casa con el ruego de Melibea de que devuelva el ceñidor a la criada y de que la vieja acuda a verla, pues le aqueja un dolor de corazón:

Celestina. Hija Lucrecia, dejadas esas razones, querría que me dijeses a qué fue agora tu buena venida.

Lucrecia. Por cierto ya se me había olvidado mi principal demanda y mensaje con la memoria de ese tan alegre tiempo como has contado, y así me estuviera un año sin comer, escuchándote, y pensando en aquella vida buena que aquellas mozas gozarían, que me parece y semeja que estó yo agora en ella. Mi venida, señora, es lo que tú sabrás: pedirte el ceñidero. Y demás desto, te ruega mi señora sea de ti visitada, y muy presto, porque se siente muy fatigada de desmayos y de dolor del corazón. (218)

No obstante, la alcahueta se niega a devolver el ceñidor a Lucrecia y le dice que ella misma lo llevará consigo a casa de Melibea:

Celestina. ¿Qué dices, hija?

LuCRECIA. Madre, que vamos presto y me des el cordón.

Celestina. Vamos, que yo le llevo. (218)

En la segunda conversación entre Celestina y Melibea en el acto $\mathrm{X}$, sólo la segunda habla de cordón y lo hace en pasado, como si el objeto no estuviese presente:

Melibea. ... ¡ Oh vieja sabia y honrada, tú seas bienvenida! ¿Qué te parece cómo ha quesido mi dicha y la fortuna ha rodeado que yo tuviese de tu saber necesidad, para que tan presto me hobieses de pagar en la misma moneda el beneficio que por ti me fue demandado para ese gentilhombre que curabas con la virtud de mi cordón? (220)

madness in the lover, but the rapture that Calisto feels upon touching an object that had hugged Melibea's body so intimately is insufficient to explain such a reaction. The devil's work had indeed gone far beyond the specific task for which he had been summoned" (125). 
Melibea. . . Cerrado han tus puntos mi llaga, venida soy en tu querer. En mi cordón le llevaste envuelta la posesión de mi libertad. Su dolor de muelas era mi mayor tormento, su pena era la mayor mía. (228)

Al final, parece como si Celestina se las ingeniara para quedarse con el ceñidor de Melibea. Peter Dunn, sin dudar de esta lectura, interpretaba dicha circunstancia como la imposibilidad de restaurar la virginidad y la rendición irreparable del "valor ético" que representaba el cordón:

The familiar symbol of female chastity, the girdle, passes from Melibea to Calisto, through the hands of the broker Celestina; needless to add, it is never returned. It cannot be returned and not only for the literal reason that virginity once surrendered cannot be restored, but because the transfer of the object has signified the surrender of the ethical value for which it stood. From that moment, the object ceases to be a symbol and is merely an object. $(414)^{12}$

Admitiendo que Celestina se queda con el cordón, se podría establecer un paralelismo con los avatares que sufrían muchas reliquias, robadas con frecuencia durante la Edad Media. ${ }^{13}$ Por supuesto, dado que la alcahueta posee una abastecida colección de objetos mágicos y un laboratorio de sustancias milagrosas, aunque no se acepte que fuerzas sobrenaturales operen el cambio de Melibea, cumple reconocer que Peter Russell acierta cuando sostiene que a la alcahueta le interesaba esta prenda para sus actividades hechiceriles (Rojas, La Celestina. Comedia o Tragicomedia de Calisto y Melibea 332 n94). ${ }^{14}$ No perdamos tampoco de vista que Melibea no lo reclama en su segunda entrevista con la tercera en el acto X. El detalle no tiene nada de baladí; antes bien parece un silencio elocuente, un último dardo de una soterrada y acerba burla en torno al culto a las reliquias.

En este punto conviene preguntarse si hubo en la Castilla de finales del siglo XV críticas parecidas. Desde luego, no será hasta la reacción de Erasmo, Lutero y Calvino cuando se produzca, fruto de una reflexión profunda, una denuncia sólida de las extravagancias del culto a las reliquias con impacto generalizado dentro del Cristianismo. Hay coincidencia en considerar la obra de Guibert de Nogent De pignoribus

\footnotetext{
${ }^{12}$ Deyermond pensaba que Dunn estaba equivocado en este punto, pero no atribuía mayor importancia a dilucidar el paradero final del cordón (30 n13).

${ }^{13}$ Sobre los furta sacra y los traslados de reliquias en Europa pude verse Patrick Geary. Luis Girón-Negrón estudia el caso español y demuestra la influencia de esta tradición en el prólogo del Zifar.

${ }^{14}$ La misma idea apuntan Severin y Cabello (Rojas, La Celestina 191, n. 30).
} 
sanctorum (circa 1120) como una excepción a esa regla. Se trata, en cualquier caso, de un tratado que apenas se difundió (Colin Morris). Bromas a propósito de reliquias absurdas como las que figuran en el Decamerón (jornada sexta, cuento décimo [Boccaccio 430-42]) tampoco significan una corriente de pensamiento estructurada que ponga en tela de juicio su culto. Para el caso concreto de la Edad Media castellana, Antonio Garrosa Resina ha hecho un repaso de las alusiones a reliquias inverosímiles en textos literarios sin observar en ellos un racionalismo escéptico que denuncie supercherías. Un caso aparte, ya en la primera mitad del siglo XV, es Pedro Tafur en sus Andanzas $y$ viajes: "los comentarios socarrones que a menudo inserta, sobre todo después de contar sucesos o historias fantásticas, denotan bien a las claras su posición de observador crítico" (Garrosa Resina 133).

No obstante, en el contexto histórico-cultural inmediato de la Celestina sí encontramos una opinión muy cercana a la sensibilidad erasmista. En la Castilla de la época de los Reyes Católicos, en donde la corrupción del clero y la ignorancia religiosa eran rampantes, Fray Hernando de Talavera (m. 1507) alzó su voz para denunciar la degeneración de estas prácticas religiosas y la superchería en torno al poder curativo de los despojos sagrados, y no vaciló en considerarlo un pecado en su Breve forma de confesar. Aclaremos que, aún cuando al monje jerónimo no le entusiasme el fervor popular por las reliquias, su censura ni mucho menos se aproxima al extremo de negar su culto. De hecho, advierte de que pecan los que no les tributan el debido respeto:

Otras maneras de sacrilegios que se comenten no tratando bien las cosas sagradas En este pecado caen los que con poco temor de Dios Nuestro Señor, e sin ningún conoscimiento de lo que el santo altar representa, y de las santas reliquias que comúnmente en los altares se ponen, se asientan de espaldas a ellos, y mucho más pecan cuando esto facen en menosprecio del precioso cuerpo de Jesucristo, si ende está encerrado. (Talavera 19-20)

En afirmaciones como ésta Talavera enlaza con una tradición arraigada. En el Libro de las confesiones (siglo XIV) Martín Pérez también se preocupaba por que se honraran las reliquias y abominaba de los que las robaban o daban a adorar reliquias falsas. ${ }^{15}$ Sin embargo, en su tratado de confesión fray Hernando va mucho más allá. Dentro

\footnotetext{
15"Demanda si dexo el Cuerpo de Dios sin çerradura, o las reliquias, ca muchos males suelen por ende contesçer. Si non honro bien las reliquias de la iglesia, non las poniendo en lugar honrado, esomismo el Cuerpo de Dios, que es mejor que todas las reliquias. Si fizo al pueblo adorar reliquias nuevas falsas o que non sopiese donde se eran, ca esto es gran pecado" (Martín Pérez 385).
} 
del epígrafe que dedica a "Otras maneras de sacrilegios que se comenten no tratando bien las cosas sagradas," especifica:

Item, cometen sacrilegio los que sacan las reliquias de las arcas donde están, y descubiertamente las muestran al pueblo y ge las dan a besar, y ge las ponen por acá y por allá por buen sacadinero.

Y pecan los que sabiéndolo las ven o adoran o consienten poner sobre sí, porque dan favor o consentimiento a la cobdicia con que los guardadores dellas se mueven a las mostar y tractar así rahezmente. (Talavera 21)

Asimismo, dentro del epígrafe sobre los "Pecados que llaman a tentar a Dios," declara:

Item, pecan en este primer mandamiento los que tientan a Nuestro Señor pidiéndole que los libre o ayude milagrosamente, pudiendo ellos proveer a sus necesidades por vía humana.

Item, los que en sus necesidades confían más de los hombres que de Nuestro Señor, y en este pecado paresce que caen los que pudiendo curar sus llagas o enfermedades con médicos y cirujanos aprovados e por vías naturales, se curan con enxalmos o van a buscar solamente las reliquias de los santos. (Talavera 22)

Talavera se expresa como un riguroso moralista desde la razón y el sentido común, criticando excesos y supersticiones. En palabras de Francisco Márquez Villanueva, exégeta del espíritu iluminista del jerónimo, el "núcleo de cristalización [de la doctrina de Fray Hernando] no es otro que las ideas expuestas en las Epistolas de San Pablo, de quien deriva todo el concepto axial del cuerpo místico ... y la hipocresía de las prohibiciones exteriores y ceremoniales" (Investigaciones sobre Juan Álvarez Gato 123). ${ }^{16}$ Empleando un argumento a fortiori, si a Talavera le indigna que se usaran las reliquias de las iglesias para curar, qué no pensaría sobre que el pueblo creyera que objetos de particulares que habían tocado reliquias sanasen a los enfermos. Sin duda, Talavera nada contracorriente y cabe imaginar que su postura respecto a las reliquias exacerbó aún más a unos enemigos que lograrían, en último término, llevar al confesor de la reina Isabel ante la Inquisición. La gran ironía en el caso de Talavera es que, a su muerte, como gozaba de fama de santo, el pueblo se lanzó a buscar sus reliquias, a las que se les atribuyeron poderes curativos (Pedro de Alcántara Suárez y Muñano 310-13).

\footnotetext{
${ }^{16}$ Aparte de la monografía de Isabella Iannuzzi, un libro fundamental sobre Talavera que acaba de aparecer, y conozco corrigiendo pruebas de este artículo, es el de Francisco Javier Martínez Medina y Martín Biersack. Miguel Ángel Ladero Quesada ha escrito también un documentadísimo artículo sobre el personaje que es trabajo de referencia.
} 
Las citas de Talavera confirman que la denuncia de los excesos en la veneración de las reliquias había arraigado en una minoría de espíritus inconformistas de la Castilla del siglo XV. Sin embargo, aunque la Celestina presente puntos de contacto con esas corrientes, su pensamiento transcurre por derroteros bien distintos. En la Tragicomedia la ironía y el sarcasmo se revisten de un tono corrosivo por la hipérbole empleada, por cómo Melibea entrega su venerable cordón de forma tan indolente a una hechicera y por cómo una prenda de virtudes divinas se nutre de un simbolismo erótico. Además, la parodia se inserta en un texto en donde se hace una sátira implacable del clero y menudean las bromas obscenas e impías a propósito de imágenes religiosas, un texto en el que, por si fuera poco, se recrea un mundo sin Providencia. Hallo difícil que semejante despliegue satírico se corresponda con un autor o autores de una severa moralidad cristiana y con una clara voluntad de cambiar costumbres. Recordemos lo que Juan Luis Vives en su Introductio ad Sapientam (1524) decía sobre los que se burlaban de la religión: "Es una impiedad mofarse de las cosas sagradas o convertir las sentencias de la Sagrada Escritura en juegos, impertinencias, cuentos de vieja o burlas, de modo similar al que esparce el cieno sobre la medicina preparada para la curación. Mas aplicarlas a un uso obsceno es, en verdad, impío y abominable” (53).

En los últimos años varios estudiosos han defendido la ausencia de fe cristiana en la Celestina, superando las lecturas que lo explicaban todo por el factor converso. ${ }^{17}$ Es curioso notar cómo, a pesar de partir de premisas distintas, se perciben llamativos puntos de confluencia en estos trabajos. Dentro de la orientación crítica trazada por Stephen Gilman, pero profundizando considerablemente en su visión del hecho converso, Márquez Villanueva entiende que la clave del pensamiento de Rojas reside en el aristotelismo heterodoxo o averroísmo radical ("Nasçer e morir como bestias"”; "El caso del averroísmo popular español”; "La Celestina y los desarrados"; "2008: Suma y sigue de La Celestina”). Desde planteamientos muy opuestos (teniendo como horizonte el humanismo italiano) y sin fijarse en el elemento converso, Di Camillo arguye que en la Celestina se detecta una "insidiosa libertad moral ... que sin atenerse a ninguna doctrina específica tiende a minar valores ético-religiosos comúnmente aceptados para abrir un espacio alternativo al de la certidumbre dogmática" ("Ética humanística y libertinaje” 593). Desde reflexiones dentro del ámbito

\footnotetext{
${ }^{17}$ Sobre los peligros de sobre interpretar leyendo siempre "en clave conversa," véase Nicasio Salvador Miguel y, en la misma línea, el reciente libro de Juan Antonio Sánchez Fernández.
} 
de la teoría de la literatura, Jesús G. Maestro no duda en afirmar que en la Tragicomedia "la religión, como sentimiento, es un ejercicio de hipocresía, de cinismo, de parodia, al fingir e invocar unas creencias que se adulteran eficazmente en el curso de la vida práctica" (202). ${ }^{18}$

Si como asegura María José Vega Ramos, "es erróneo sostener que la incredulidad fuera imposible antes de 1650" (272), si en la Tragicomedia "on n'est pas loin du rationalisme" (Joseph Pérez 28), cabe preguntarse hasta qué punto detrás de esa mirada escéptica al culto a las reliquias en la Celestina pudiera latir, aunque de forma velada, la misma falta de fe que alarmaba ver al propio fray Hernando de Talavera en la Castilla donde nació la obra. Por supuesto, la interesante cita también arroja luz sobre cómo determinados lectores de la época pudieron entender el desmoronamiento espiritual del inconsolable Pleberio en el último acto:

Item, peca el que no confiesa por la boca y obras la santa fe, cuando es necesario, así como si alguno fuese preguntado della y callase; y porque calló, pensasen los presentes que él no tenía fe, o que pues él calla, la fe no es verdadera; o si otros, por verle callar, perdiesen la fe que tienen; y aún peca, aunque no sea preguntado, si ve en cualquier manera peligrar la fe, y no hace lo que puede por la defender; y aún Sant Agustín dice que cuando nos acostamos y cuando nos levantamos, avemos de decir el Credo in Deum. (Talavera 4, el énfasis es mío) ${ }^{19}$

Universidad Complutense de Madrid

\section{OBRAS CITADAS}

Amasuno, Marcelino V. Sobre la aegritudo amoris y otras cuestiones fisiátricas en La Celestina. Madrid: CSIC, 2005. Impreso.

Beresford, Andrew M. "Una oración, señora, que le dixeron que sabías, de Sancta Polonia para el dolor de muelas': Celestina and the Legend of St. Appollonia.” Bulletin of Hispanic Studies 78.1 (2001): 39-58. Impreso.

\footnotetext{
${ }^{18}$ Frente a estas posturas, en la introducción de su imprescindible edición de la Comedia, retomando y ampliando trabajos suyos anteriores, José Luis Canet Vallés aboga por el valor moral de la obra (Comedia de Calisto y Melibea 11-165).

${ }^{19}$ Este artículo se enmarca dentro de las actividades del proyecto de investigación del Ministerio de Ciencia e Innovación FFI2008-01280 y del grupo de investigación de la Universidad Complutense de Madrid 941.032, dirigidos ambos por el profesor Nicasio Salvador Miguel, a quien agradezco su apoyo en mis indagaciones. Estoy en deuda también con todos los colegas con los que he conversado de esta investigación y me han aportado ideas y sugerencias: Pablo Ancos-García, Ivy Corfis, Jean Dangler, Ottavio Di Camillo, Luis Girón-Negrón, Ángel Gómez Moreno, Ainara Herrán Martínez de San Vicente, Luce López Baralt, Francisco Márquez Villanueva, Devid Paolini, Joseph Snow, Felipe Valencia, Mercedes Vaquero y Ana Villar.
} 
Boccaccio, Giovanni. Il Decamerone. Ed. Luigi Giavardi. Milano: Lucchi, 1972. Impreso.

Castañega, Martín de. Tratado de las supersticiones y hechicerías y de la posibilidad y remedio de ellas (1529). Ed. Juan Roberto Muro Abad. Logroño: Instituto de Estudios Riojanos, 1994. Impreso.

Castillo Castillo, José. "El consumo medieval de reliquias de santos." Religión y sociedad en España y los Estados Unidos: Homenaje a Richard A. Schoenherr. Ed. José Pérez Vilariño. Madrid: Centro de Investigaciones Sociológicas, 2003. 29-47. Impreso.

Comedia de Calisto y Melibea. Ed. José Luis Canet Vallés. Valencia: Publicacions de la Universitat de València, 2011. Impreso.

Dangler, Jean. Mediating Fictions: Literature, Women Healers, and the Go-Between in Medieval and Early Modern Iberia. London: Associated University Presses, 2001. Impreso.

Deyermond, Alan. "Hilado-cordón-cadena: equivalencia simbólica en La Celestina." 1977. Medievalia 40 (2008): 27-32. Impreso.

Di Camillo, Ottavio. "Ética humanística y libertinaje en La Celestina." 1999. Estudios sobre la Celestina. Ed. Santiago López-Ríos. Madrid: Istmo, 2001. 579-98. Impreso.

_. "When and Where Was the First Act of La Celestina Composed? A Reconsideration.” Paolini 91-155. Impreso.

Dunn, Peter. "Pleberio's World." Publications of the Modern Language Association of America 91 (1976): 406-19. Impreso.

An Edition of the First Italian Translation of the Celestina. Ed. Kathleen V. Kish. Chapel Hill: The U of North Carolina P, 1973. Impreso.

Fernández, Enrique. "El simbolismo de la menstruación en La Celestina." Paolini 158-70. Impreso.

Fontes, Manuel da Costa. The Art of Subversion in Inquisitorial Spain: Rojas and Delicado. West Lafayette: Purdue UP, 2005. Impreso.

Garrosa Resina, Antonio. "La fantasía de las reliquias inverosímiles en las letras medievales castellanas.” Castilla. Estudios de Literatura 11 (1986): 123-37. Impreso.

Gato, Juan Álvarez. Obras completas. Ed. J. Artiles. Madrid: n.e., 1928. Impreso.

Geary, Patrick. Furta Sacra: Thefts of Relics in the Central Middle Ages. Princeton: Princeton UP, 1978. Impreso.

Gerli, E. Michael. "El placer de la mirada: voyeurismo, fetichismo y la movilización del deseo en Celestina." El mundo social y cultural de La Celestina: Actas del Congreso Internacional, Universidad de Navarra, junio, 2001. Eds. Ignacio Arellano y Jesús M. Usunáriz. Madrid-Frankfurt: Iberoamericana-Vervuert, 2003. 191-208. Impreso.

Giles, Ryan D. The Laughter of the Saints: Parodies of Holiness in Late Medieval and Renaissance Spain. Toronto: U of Toronto P, 2009. Impreso.

Gilman, Stephen. La España de Fernando de Rojas: Panorama intelectual y social de La Celestina. 1972. Madrid: Taurus, 1978. Impreso.

Girón-Negrón, Luis. “'Commo a cuerpo santo’: el prólogo del Zifar y los furta sacra hispano-latinos.” Bulletin Hispanique 102.2 (2001): 345-68. Impreso.

Gómez Moreno, Ángel. Claves hagiográficas de la literatura española: Del Cantar de Mio Cid a Cervantes. Madrid-Frankfurt am Main: Iberoamerican-Vervuert, 2008. Impreso.

—. "Lecciones de hagiografía en La Celestina." Paolini 91-155. Impreso.

—_ y Teresa Jiménez Calvente. "A vueltas con Celestina-bruja y el cordón de Melibea.” Revista de Filología Española 75.1-2 (1995): 85-104. Impreso.

González-Echevarría, Roberto. La prole de Celestina: Continuidades del barroco en las literaturas española e hispanoamericana. 1993. Madrid: Colibrí, 1999. Impreso. 
Hernando Sánchez, Carlos José. "Un tratado español sobre la corte de Roma en 1504: Baltasar del Río y la sátira anticortesana.” Roma y España: Un crisol de la cultura europea en la Edad Moderna. Actas del Congreso Internacional celebrado en la Real Academia de España en Roma del 8 al 12 de mayo de 2007. Ed. Carlos José Hernando Sánchez. Vol. 1. Madrid: Sociedad Estatal para la Acción Cultural Exterior, 2007. 189-237. Impreso.

Herrero, Javier. “The Stubborn Text: Calisto's Toothache and Melibea's Girdle.” Literature among Discourses: the Spanish Golden Age. Eds. Wlad Godzich y Nicholas Spadaccini. Minneapolis: U of Minnesota P, 1986. 132-47. Impreso.

Herrmann-Mascard, Nicole. Les reliques des saints: Formation coutumière d'un droit. París: Éditions Klincksieck, 1975. Impreso.

Huizinga, Johan. El otoño de la Edad Media: Estudios sobre la forma de la vida y del espiritu durante los siglos XIV y XV en Francia y en los Países Bajos. 1919. Madrid: Alianza Editorial, 1985. Impreso.

Iannuzzi, Isabella. El poder de la palabra en el siglo XV: Fray Hernando de Talavera. Salamanca: Junta de Castilla y León, 2009. Impreso.

Interludio de Calisto y Melibea. Eds. Antonio López Santos y Rubén Tostado González. Salamanca: Ediciones Universidad de Salamanca, 2001. Impreso.

Ladero Quesada, Miguel Ángel. "Fray Hernando de Talavera en 1492: de la corte a la misión." Chronica Nova 34 (2008): 249-75. Impreso.

López-Ríos, Santiago. "La oración a Santa Apolonia de la Celestina a la luz del folklore médico-religioso." La dramaturgia de la 'Celestina'. Ed. Jesús G. Maestro y José María Ruano de la Haza. Spec. issue of Theatralia: Revista poética del teatro 10 (2008): 59-76. Impreso. Accesible también en <http://eprints.ucm.es/8585/>.

— _ "Ver la 'grandeza de Dios' en la Celestina: más allá del tópico de la hipérbole sagrada." Paolini 206-25. Impreso. Accesible también en <http://eprints.ucm. es/13303/>.

Maestro, Jesús G. "Idea de libertad en La Celestina desde el materialismo filosófico como teoría de la literatura." Celestinesca 32 (2008): 191-207. Impreso.

Márquez Villanueva, Francisco. Investigaciones sobre Juan Álvarez Gato: Contribución al conocimiento de la literatura castellana del siglo XV. Madrid: Real Academia Española, 1960. Impreso.

"“Nasçer e morir como bestias' (criptojudaísmo y criptoaverroísmo)." Los judaizantes en Europa y la literatura castellana del Siglo de Oro. Ed. Fernando Díaz Esteban. Madrid: Letrúmero, 1994. 273-93. Impreso.

. "El caso del averroísmo popular español. (Hacia La Celestina)." Cinco siglos de Celestina: aportaciones interpretativas. Eds. Rafael Beltrán y José Luis Canet. Valencia: Universitat de València, 1997. 121-32. Impreso.

Santiago: trayectoria de un mito. Barcelona: Edicions Bellaterra, 2004. Impreso.

"La Celestina y los desarrados." Siglos dorados: Homenaje a Augustin Redondo. Ed. Pierre Civil. Vol. 2. Madrid: Castalia, 2004. 889-902. Impreso.

"2008: Suma y sigue de La Celestina." Late Medieval Studies in Honour of Dorothy Sherman Severin. Eds. Joseph T. Snow y Roger Wright. Liverpool: Liverpool UP, 2009. 182-88. Impreso.

Martínez Medina, Francisco Javier y Martín Biersack. Fray Hernando de Talavera, primer arzobispo de Granada: Hombre de Iglesia, estado y letras. Granada: Universidad de Granada, 2011. Impreso.

Morris, Colin. "A Critique of Popular Religion: Guibert of Nogent on The Relics of the Saints." Popular Belief and Practice: Papers Read at the Ninth Summer Meeting and the Tenth Winter Meeting of the Ecclesiastical History Society. Eds. G. J. Cuming y Derek Baker. Cambridge: Cambridge UP, 1972. 55-60. Impreso. 
Paolini, Devid, ed. "De ninguna cosa es alegre posesión sin compañia." Estudios celestinescos y medievales en honor del profesor Joseph Thomas Snow. Vol. 1. Nueva York: Hispanic Seminary of Medieval Studies, 2010.

Pérez, Joseph. "La Célestine, livre converso ou livre de converso." Fernando de Rojas: La Celestina. Comedia o Tragicomedia de Calisto y Melibea. Ed. Georges Martin. París: Ellipses, 2008. 21-29. Impreso.

Pérez, Martín. Libro de las confesiones: Una radiografia de la sociedad medieval española. Eds. Antonio García y García et al. Madrid: Biblioteca de Autores Cristianos, 2002. Impreso.

Pornoboscodidascalus latinus (1624): Kaspar Barth's Neo-latin Translation of Celestina. Ed. Enrique Fernández. Chapel Hill: U of North Carolina P, 2006. Impreso.

Rojas, Fernando de. Celestina: Tragicomedia de Calisto y Melibea. Ed. Miguel Marciales et al. 2 vols. Urbana-Chicago: U of Illinois P, 1985. Impreso.

—. La Celestina. Ed. Dorothy S. Severin y Maite Cabello. Madrid: Editorial Cátedra, 1988. Impreso.

Rojas, Fernando de (y "antiguo autor"). La Celestina: Tragicomedia de Calisto y Melibea. Eds. Francisco J. Lobera et al. Barcelona: Crítica, 2000. Impreso.

Rojas, Fernando de. La Celestina: Comedia o Tragicomedia de Calisto y Melibea. Ed. Peter Russell. Madrid: Editorial Castalia, 2001. Impreso.

Salvador Miguel, Nicasio. "El presunto judaísmo de La Celestina." The Age of the Catholic Monarchs (1474-1516): Literary Studies in Memory of Keith Whinnom. Eds. Alan Deyermond e Ian Macpherson. Liverpool: Liverpool UP, 1989. 162-77. Impreso.

Sánchez Fernández, Juan Antonio. La tesitura de La Celestina. Praga: Karolinum, 2011. Impreso.

Seidenspinner-Núñez, Dayle. "The Poetics of (Non)Conversion: The Vida de Santa María Egipçiaca and La Celestina." Medievalia et Humanistica: Studies in Medieval and Renaissance Culture 18 (1992): 95-128. Impreso.

Shipley, George. "Concerting through Conceit: Unconventional Uses of Conventional Sickness Images in La Celestina." Modern Language Review 70.2 (1975): 324-32. Impreso.

Snow, Joseph T. "Alisa, Melibea, Celestina y la magia." 1999. Estudios sobre la Celestina. Ed. Santiago López-Ríos. Madrid: Istmo, 2001. 312-24. Impreso.

Suárez y Muñano, Pedro de Alcántara. Vida del venerable D. Fray Hernando de Talavera, primer arzobispo de Granada, confesor y consejero de los Reyes Católicos, D. Fernando y $D^{a}$ Isabel. Madrid: n.e., 1886. Impreso.

Sumption, Jonathan. The Age of Pilgrimage: The Medieval Journey to God. 1975. Mahwah: HiddenSpring, 2003. Impreso.

Talavera, Hernando de. Breve forma de confesar, reduciendo todos los pecados mortales y veniales a los diez mandamientos. Escritores místicos españoles. Ed. Miguel Mir. Madrid: Casa Editorial Bailly-Baillière, 1911. 3-31. Impreso.

Vasvári, Louise O. "Glosses on the Vocabu(r) lario of the Celestina: II. El dolor de muelas de Calisto." Late Medieval Spanish Studies in Honour of Dorothy Sherman Severin. Eds. Joseph T. Snow y Roger Wright. Liverpool: Liverpool UP, 2009. 170-81. Impreso.

Vega Ramos, María José. "La biblioteca del ateo en el Quinientos.” Letras humanas y conflictos del saber: La filología como instrumento a través de las edades. Eds. Ana Vian Herrero y Consolación Baranda Leturio. Madrid: Editorial Complutense, 2008. 261-301. Impreso.

Vives, Juan Luis. Introductio ad Sapientiam: Introducción a la sabiduría. Trad. Ismael Roca Meliá y Angel Gómez-Hortigüela. Valencia: Ajuntament de València, 2001. Impreso. 